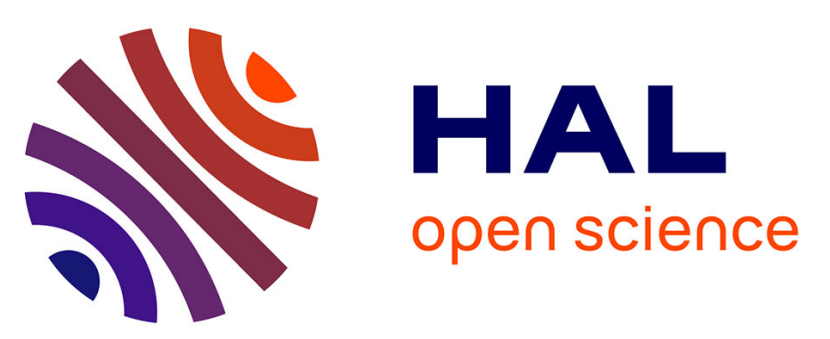

\title{
How stressors are dynamically appraised within a team during a game: An exploratory study in basketball
}

\author{
Julie Doron, Jérôme Bourbousson
}

\section{To cite this version:}

Julie Doron, Jérôme Bourbousson. How stressors are dynamically appraised within a team during a game: An exploratory study in basketball. Scandinavian Journal of Medicine and Science in Sports, 2017, 27 (12), pp.2080-2090. 10.1111/sms.12796 . hal-01579163

\section{HAL Id: hal-01579163 \\ https://hal-insep.archives-ouvertes.fr/hal-01579163}

Submitted on 13 Jul 2020

HAL is a multi-disciplinary open access archive for the deposit and dissemination of scientific research documents, whether they are published or not. The documents may come from teaching and research institutions in France or abroad, or from public or private research centers.
L'archive ouverte pluridisciplinaire HAL, est destinée au dépôt et à la diffusion de documents scientifiques de niveau recherche, publiés ou non, émanant des établissements d'enseignement et de recherche français ou étrangers, des laboratoires publics ou privés. 
STRESSORS WITHIN TEAM GAMES

1 Doron, J., \& Bourbousson, J. (2017). How stressors are dynamically appraised within a

2 team during a game: An exploratory study in basketball. Scandinavian Journal of

3 Medicine \& Science in Sports, 27(12), 2080-2090. https://doi.org/10.1111/sms.12796

4

5

6

8

9

10

17 Date of submission: 04/10/2016

18 Word count: 5,063 words (excluding references, figures and tables) exploratory study in basketball

Julie DORON $\bowtie$
French National Institute of Sport, Expertise and Performance, Research Department, Laboratory of Sport, Expertise and Performance (EA 7370), France Jérôme BOURBOUSSON
Sport Sciences Faculty, University of Nantes, Laboratory "Movement, Interactions, Performance", (EA 4334), France 
STRESSORS WITHIN TEAM GAMES

1

2 Little is known about how team sport athletes individually and collectively experience sources of

3 stress during competitive sport encounters. This study aimed to examine the nature of the

$4 \quad$ stressors team sport athletes appraised during games at individual and team levels, as well as their

5 degree of synchronization during an unfolding game. Through individual self-confrontation

6 interviews, the activities of nine basketball players of the same team were examined in detail. The

7 results revealed that twelve categories of stressors were reported, and categorized into two larger

8 units reflecting stressors perceived as affecting (i) "the team functioning as a whole" and (ii) "a

9 player's own functioning". Thus, the nature and degree of similarity of the game-specific

10 stressors experienced by basketball players within a single team were identified during a game. In

11 addition, the findings showed six different patterns of synchronizations of team members'

12 stressors, as well as their changes over the course of the game. They provided support for the

13 synchronized appraisal and experience of stressors within a team during a game. By adopting an

14 interpersonal perspective and examining the temporal interplay in team members' activities, this

15 study shed light on stress within teams.

16

17 Keywords: stress, intrapersonal and interpersonal perspectives, team sports, team dynamics, team

18 functioning

19

20

21 
STRESSORS WITHIN TEAM GAMES

\section{Introduction}

Given the highly complex social environment surrounding competitive sport, stress appears to be an inherent aspect of athletic performance (Fletcher, Hanton, Mellalieu, \& Neil, 2012). Stress is a process that occurs as the result of a transaction, or reciprocal effects, between athletes and their environment (Hoar, Crocker, Holt, \& Tamminen, 2010; Lazarus, 2000). Sources of stress within these transactions are called stressors and refer to demands that individuals appraise as taxing or exceeding his or her resources (Hoar, Kowalski, Gaudreau, \& Crocker, 2006). There are numerous potential stressors in sport (e.g., Hoar et al., 2010) that are often social in nature (Tamminen \& Gaudreau, 2014). However, there is considerably less research focusing on how stressors in team sports are individually and collectively appraised and experienced during competitive sport encounters. Hence, the goal of this study was to: (a) examine the nature of the stressors encountered by basketball team members during a game, (b) explore the extent to which these stressors were similarly appraised and experienced, and (c) explore the extent to which these stressors were simultaneously appraised and experienced during an unfolding game.

Over the past couple of decades, sport psychology researchers have focused on identifying and categorizing the different events or situations athletes appraise as stressors (e.g., Arnold \& Fletcher 2012; Fletcher et al., 2012; Noblet \& Gifford, 2002; Scanlan, Stein, \& Ravizza, 1991). Recently, the meta-interpretation of Arnold and Fletcher (2012) synthesized the findings of 34 qualitative studies and provided a comprehensive taxonomy of 640 distinct organizational stressors encountered by a large, wide-ranging cohort of athletes. They found four main categories: leadership and personnel issues, cultural and team issues, logistical and environmental issues, and performance and personal issues. Some of these studies focused specifically on team 
STRESSORS WITHIN TEAM GAMES

1 sports and identified specific stressors appraised by team sport athletes (e.g., Anshel \& Wells,

2 2000; Holt \& Dunn, 2004; Holt \& Hogg, 2002; Madden, Summers, \& Brown, 1990; Nicholls \&

3 Polman, 2007; Nicholls, Holt, Polman, \& Bloomfield, 2006; Nicholls, Backhouse, Polman, \&

4 McKenna, 2009; Nicholls, Jones, Polman, \& Borkoles, 2009; Noblet \& Gifford, 2002; Reeves,

5 Nicholls, \& McKenna, 2009). For example, Nicholls and Polman (2007) found that the most

6 salient stressors of under 18-year old international adolescent rugby union players were physical

7 errors, receiving coach/parental criticism, making a mental error, injury, and observing an

8 opponent play well. With a sample of basketball players, Anshel and Wells (2000) identified 25

9 sources of stress classified into five categories: interpersonal conflicts, refereeing decisions,

10 personal performance problems, opposition influences, and team behaviour. However, at present,

11 little is known about team sport athletes' communal appraisal and experience of these stressors in

12 specific sport situations (e.g., games). A key limitation of these studies is that stressors in team

13 sports have largely been explored from an individualistic or intrapersonal perspective focusing on

14 how each individual in a team appraises and experiences internal or/and external events as

15 stressors (Tamminen \& Gaudreau, 2014). Furthermore, previous studies did not explore to what

16 extent the stressors individually appraised were also appraised and experienced by teammates at

17 the same or different times during specific sport situations. To our knowledge, the sport

18 psychology literature has failed to examine how team sport athletes individually and collectively

19 appraise and experience sources of stress during competitive sport encounters.

Although researchers have largely tended to focus on individual athletes' perceptions of

21 stressors (i.e., intrapersonal perspective), athletes' stressors are often social in nature and stem

22 from social interactions such as arguments or disagreements between teammates, being criticized

23 or yelled at by parents or coaches, getting a bad call by an official, and interpersonal performance 
STRESSORS WITHIN TEAM GAMES

1 or relationship conflicts (Arnold \& Fletcher 2012; Tamminen \& Gaudreau, 2014). The results of

2 Campo and colleagues' (2012) systematic review highlighted the importance of social influences

3 on team sport athletes' emotional experiences, as the influence of others (e.g., negative

4 relationships, criticism, teammates' behaviours) was identified as an antecedent of athletes'

5 negative emotions in over $58 \%$ of the studies they reviewed, whereas athletes' own errors (e.g.,

6 physical or mental errors) were reported as antecedents of negative emotions in $52.9 \%$ of the

7 studies reviewed. Team members may potentially influence the emotions or behaviours of

8 teammates through the conscious or unconscious induction of emotions, as reflected in the

9 phenomenon of emotional contagion (Hatfield, Cacioppo, \& Rapson, 1994). Consequently, there

10 is a clear need to also explore how athletes' stressor appraisals influence and are influenced by

11 other team members during their common unfolding team activity and to what extent sources of

12 stress are shared by teammates during sport encounters (i.e., interpersonal perspective). As such,

13 an interpersonal perspective also considers how athletes appraise stressors as a group, reflecting

14 athletes' perceptions of how "we as a team are appraising events and situations" (Tamminen \&

15 Gaudreau, 2014). Furthermore, stress occurs as a process that changes over time (Lazarus, 1999;

16 Nicholls et al., 2006, 2009). To achieve a more complete understanding of team sport athletes'

17 stressors, it seems necessary to consider the different stressors team sport athletes experience at

18 both individual and/or team levels and their temporal aspects.

19 Given the complex and dynamic nature of the relationship between athletes and their

20 environment (Lazarus, 2000), a focus on team sport athletes' perceptions of stressors also calls

21 for scrutinizing temporal aspects of the transaction. Although the way an individual athlete

22 experiences the team setting may be very distinct from the way it is experienced by his or her

23 teammates (Bourbousson, Poizat, Saury, \& Sève, 2011), evidence of moment-to-moment 
STRESSORS WITHIN TEAM GAMES

1 contagion phenomena during a game have been provided in team sports (Bourbousson, Poizat,

2 Saury, \& Sève, 2012; Bourbousson, R'Kiouak, \& Eccles, 2015). In their study of the way in

3 which basketball players simultaneously understand the unfolding game, Bourbousson et al.

4 (2012) showed that temporal descriptions of individual courses of action and how these courses

5 of action interplay were heuristics for disentangling the way different interpretations of a given

6 event might lead to shared understanding later in the game. Moreover, the authors pointed out

7 that verbal communication was not needed to observe such contagion phenomena (Bourbousson

8 et al., 2011). Consequently, there is a clear need to consider that sources of stress occurring

9 during sport encounters are not similar and synchronized as a matter of principle, but that

10 temporal interplay between team members' activities might occur and lead to stressors being

11 shared by teammates to a greater or lesser extent. By adopting such a temporal view of the extent

12 to which stressors are simultaneously experienced within a team, the present study should also

13 contribute to the emerging science of team microdynamics (Bourbousson et al., 2015; Humphrey

14 \& Aime, 2014; Li \& Roe, 2012).

The present study aimed to address the lack of knowledge about how stressors in team

16 sports are individually and collectively appraised and experienced during competitive sport

17 encounters. Consequently, the nature of the stressors team sport athletes appraised during games

18 was explored at individual and team levels, as well as their degree of synchronization during an

19 unfolding game.

20 2. Method

21 2.1. Participants

Nine French male basketball players (mean \pm SD; age $17.11 \pm 0.60$ years; experience

23 playing competitive basketball $8.22 \pm 0.97$ years) volunteered to participate in this study. At the 


\section{STRESSORS WITHIN TEAM GAMES}

1 time of the study (November 2007), they were members of the same team, ranked number one in

2 the first division of the French Cadets Championship (i.e., the 16 best teams in the under-18

3 category). Pseudonyms were used for the athletes to ensure confidentiality. Chris, Jules and

$4 \quad$ Bertrand were guards, Guy and Bastien were small forwards, Vic and Vince were power

5 forwards, and Noé and Niels were centres. The participants' parents all signed statements of

6 consent and were informed of the athletes' right to withdraw at any time. The present study

7 obtained approval from the local University of Nantes (France) review board regarding standard

8 research practice and the guidelines outlined for research involving humans.

9 2.2. Data collection

The team members' activity was studied during an entire competitive match. The team

11 won the match in question easily (final score: 74-58), as well as the previous encounter two

12 months earlier (by a 25-point margin). Two types of data were collected: (a) continuous audio-

13 video recordings of the players' activities during the entire match and (b) verbalizations during

14 post-match interviews.

During the match, recordings were made with the audio-video camera positioned behind

and to the side of the court. A wide-angle lens filmed all players and their opponents

17 continuously. The angle was constantly adapted to follow the players' movements on-court and

18 to include the four other players waiting on the sideline as much as possible.

19 The verbalization data were gathered from individual self-confrontation interviews with

20 each of the players as soon as possible after the matches (between 24 and 48 hours post-match)

21 (see Bourbousson et al., 2011, 2012, 2015 for scientific accounts obtained using this interview

22 procedure). During the interviews, each player viewed the audio-videotape of the match together

23 with the researcher. The player was asked to describe and comment on his activity during the 
STRESSORS WITHIN TEAM GAMES

1 match (what he was doing, feeling, thinking and perceiving during the match). Prompts from the

2 interviewer were designed to obtain complementary information about the actions that were

3 meaningful to the player (e.g., "Here, you're saying that you're waiting for Chris to call the

4 play...?"). Probing questions were used to explore participants' feelings in detail. Nevertheless,

5 questions did not address the potential stressors directly, in order not to influence the players'

6 expression of their feelings. Each of the players commented on the entire match. The interviews

7 lasted an average of 75 minutes and were all recorded in their entirety using a camera and tape

8 recorder.

$9 \quad$ 2.3. Data processing

The audio-videotapes were viewed in order to draw up an inventory of the nine players'

moves. The verbal exchanges between player and researcher during the interview were recorded

12 and fully transcribed. The data were then processed in four steps (see Theureau, 2003 for details

13 of the experiential data analysis): (a) generating a log of the match, (b) reconstructing the way

14 individual players experienced the dynamics of the game, (c) synchronizing the way individual

15 players experienced the dynamics of the game, and (d) identifying what stressed the players, and

16 characterizing the extent to which these stressors were similarly and simultaneously experienced

17 by team members over the course of the match.

a. Generating match $\operatorname{logs}$

This step consisted of generating a summary table or log containing the data collected for

20 the match. The data were presented by mapping two levels of data to each other. The first level

21 pertained to the data recorded during the match (i.e., descriptions of a player's observable moves

22 and overt communications). The second level pertained to the data recorded during the post-

23 match interview (i.e., verbatim transcription of the prompted verbalizations). 
STRESSORS WITHIN TEAM GAMES

b. Reconstructing the way individual players experienced the dynamics of the game We first identified discrete meaningful units of activity that constituted the chain of events meaningful to each participant (Theureau, 2003). Each unit had personal meaning and was assumed to be the expression of the way in which the activity was experienced by the given participant at a given instant. The way these units link together over time accounts for the dynamics of a given player's experience of the game. During the period of the game under study, 249 discrete units of activity were identified for Chris's courses of action, 429 units for Jules's, 259 for Bertrand's, 224 for Guy's, 185 for Bastien's, 197 for Vic's, 243 for Vince's, 269 for Noé's, and 321 for Niels's.

c. Synchronizing the way individual players experienced the dynamics of the game In this step, we synchronized the nine ways individual players experienced the dynamics of the game by presenting them side-by-side in the same table in chronological order. To facilitate synchronization of the individual meaningful units, the objective description of the unfolding match was used to provide the ball holder's name, the timing of the players' actions, and the players' positions on the court. The synchronization of the ways in which individual players experienced their activity respectively at a given moment of the game is illustrated in Table 1.

d. Identification of sources of stress and the extent to which they are simultaneously experienced within the team This analysis comprised three steps: (a) identification of the individual stressors, (b) thematic analysis of these stressors, and (c) characterization of the extent to which these stressors were simultaneously experienced within the team over the course of the game. 
STRESSORS WITHIN TEAM GAMES

1

2 [demand, problem, difficulty] appraised and experienced as unpleasant, upsetting or perturbing

3 an athlete's current activity within the team during the game, Anshel \& Wells, 2000; Hoar et al.,

4 2006). The stressors were identified as they appeared in the units of activity forming the way

5 individual players experienced the dynamics of the game. At this stage in the processing,

6 stressors were labelled according to the experience that the given participant cited. We identified

7790 stressors experienced within the team over the course of the game.

8

9 of the stressors identified at the first step. This processing consisted in searching for patterns (i.e.,

10 commonly recurring themes) in the qualitative data set. Using a thematic analysis, the contents of

11 the stressors were grouped into larger units on the basis of two criteria: (a) the meaning of the

12 statements, and (b) the use of category definitions that were discriminating enough to avoid

13 overlapping. The categories were defined step-by-step and re-checked each time a new category

14 was created. For the 790 experienced stressors, this resulted in 12 categories, which then fitted

15 into two overarching themes. An analysis of the occurrences of these themes was then performed,

16 enabling the most prominent themes, and indicating which players experienced which particular

17 stressors. Subsequently, this analysis enabled identification of the types of stressors most

18 commonly shared by the players.

19 In the final step, we characterized the extent to which these sources of stress were

20 simultaneously experienced over the course of the game. For this, each type of stressor was

21 positioned accurately on the timeline of the activity of each individual player. A comprehensive

22 inspection of the synchrony of these occurrences resulted in the characterization of typical forms 
STRESSORS WITHIN TEAM GAMES

1 of collective arrangement of the stressors at a given instant (i.e., the way in which stressors occur

2 at team level at a given moment).

\section{3. Results}

\section{$4 \quad 3.1$. Identification of the types of stressors and their similarity across team members}

5
From the description of the activity at the level that was meaningful for the players, analysis of the elements that stressed the players during this basketball match identified 790 events. Thematic analysis of the contents of these experienced stressful events revealed 12 categories of stressors (see Table 2). This analysis further revealed that the 12 categories of stressors fit within two overarching themes, namely: (a) stressors perceived as affecting the team functioning as a whole $(n=522,66 \%)$, and (b) stressors perceived as only affecting a player's own functioning $(n=268,34 \%)$. The breakdown of the stressors across the various categories for each team member is presented in Table 2. The following sections detail the players' subjective experiences under the two main overarching themes.

a. Stressors perceived as affecting the team functioning as a whole

This theme comprised the following types of stressful events: a team member considering that the unfolding game events were potentially detrimental to the team performance during the game (e.g., the level of performance of each of the constitutive team members, the level of play of the opposing team, the current score, as well as external factors that could perturb the team functioning, such as refereeing quality). To illustrate this theme, the following excerpts from the self-confrontation interviews relate to a team member's experience during the game: "Bertrand [my teammate] asked us to develop the same tactical move as before...I was afraid that the opponents would be able to predict our moves and our positioning. He [Bertrand] has to stop calling this tactical play" (Jules, 13'30', coded A-1: Stressed by the Level of performance of a 
STRESSORS WITHIN TEAM GAMES

1 team member), and "I was lost during this defence sequence. I didn't understand what they were

2 doing: my direct opponent hadn't balanced the space, he stayed at the 3-point line and the ball

3 had been thrown to the other side of the court. I was trapped and don't understand how... such a

4 setting mustn't happen again" (Chris, 2'05', coded A-4: Stressed by the Tactical difficulty level

5 presented by the opposition).

6 b. Stressors perceived as only affecting a player's own functioning

7 This theme comprised the following type of stressful events: a given team member considered

8 that the unfolding game events were potentially detrimental to his individual performance during

9 the game. These events were of a physical or psychological nature. Physical events included pain

10 or fatigue, while social demands or mental error were psychological. External events like

11 criticism from the coach, or the opposite team changing its collective organization, were also

12 stressors able to affect the individual functioning of the team member in question. To illustrate

13 this theme, the following excerpts from the self-confrontation interviews relate to a team

14 member's experience during the game: "I was wrong to put pressure on my direct opponent, and

15 so I made a mistake in my technique, which led to the referee signalling a foul. I needed to find a

16 solution" (Guy, 18'40, coded B-1: Stressed by Personal performance problems), and "I lost the

17 thread of our team organization. I felt like I was like dreaming at that point. I couldn't remember

18 all the instructions I had to follow. I'll have to be more focused. Here I asked the assistant coach

19 to remind me of the team instructions that were given during the time-out" (Niels, 13'12, coded

20 B-2: Stressed by Mental errors).

21 3.2. Time synchronization of the types of stressors within the team

Temporal analysis of the previous descriptions of the stressors experienced within the

23 game revealed several forms of synchronization of stressors at a given instant within the team, 
STRESSORS WITHIN TEAM GAMES

1 known as characteristic collective arrangements of stressors. Six characteristic arrangements were

2 observed, namely: (a) a player made an error and this error was sufficiently serious to be

3 simultaneously a common source of stress for him and his teammates; (b) a player made an error

$4 \quad$ sufficiently serious to be a common source of stress for his teammates, without his being

5 concerned himself; (c) an external event was a common source of stress (e.g., referee, opposing

6 coach); (d) several players were simultaneously concerned by personal performance problems;

7 (e) several players were simultaneously concerned by the level of team performance as a source

8 of stress; (f) several players were simultaneously concerned by the level of opposing team

9 performance as a source of stress. Figure 1 illustrates these characteristic forms of arrangement of

10 the sources of stress within the team. These forms changed across time, fluctuating frequently so

11 that no specific temporal pattern was visible in the way the arrangements were linked together

12 from one moment to the next. Figure 2 illustrates the changes in the forms of collective

13 arrangements of stressors across time during a portion of the game.

\section{4. Discussion}

Using individual experience data collection, the purpose of this study was threefold: (a) to

16 examine the nature of the stressors encountered by team members, (b) to explore the extent to

17 which these stressors were similarly experienced, and (c) to explore the extent to which these

18 stressors were simultaneously experienced during an unfolding game. The findings provided

19 some support for Tamminen and Gaudreau's (2014) research perspectives on stress within teams.

Firstly, results highlighted that basketball players experienced a multitude of stressors

21 during a game. Twelve categories were reported and categorized into two larger units reflecting

22 stressors perceived as affecting: (a) "the team functioning as a whole" (e.g., level of performance

23 of a team member, level of performance of opponents, external factors) and (b) “a player's own 
STRESSORS WITHIN TEAM GAMES

1 functioning" (e.g., personal performance problems, mental errors, coach's criticism). Similar

2 stressors in competitive sport have been reported in previous studies (e.g., teammates' behaviours

3 and interactions, the coach's personality and attitude, performance feedback, refereeing

4 decisions, errors relating to one's own performance) (Anshel \& Wells, 2000; for review see

5 Arnold \& Fletcher, 2012; Madden et al. 1990). For example, in Anshel and Wells's (2000) study,

6 the most intense sources of stress reported by basketball players related to refereeing decisions

7 and personal performance problems. As a whole, previous studies have explored stressors in team

8 sports from an individualistic perspective and have failed to take into account the interpersonal

9 nature of sources of stress perceived as affecting team functioning. The originality of our results

10 stems from the identification of stressors appraised as affecting both individual and team

11 functioning. In addition, the present study has added to the literature by providing an original

12 focus on game-specific stressors appraised during a real game by members of one team (e.g.,

13 events during the game, tactical difficulty of opposition, ratio of power) and specifically

14 highlighted stressors related to team functioning during a game (e.g., collective demotivation,

15 score management, level of performance of opponents). To our knowledge, previous studies have

16 generally explored stressors in team sports over long periods, such as during preparation for

17 competition (e.g., Holt \& Hogg, 2002), or a season (e.g., Holt \& Dunn, 2004; Nicholls et al.,

18 2006). To date, few studies have focused on stressors experienced during an unfolding game

19 (with the exception of Anshel \& Wells, 2000) and particularly within a single team. The

20 methodological approach used in this study (i.e., video recall method) allowed exploration of

21 game-specific stressors appraised and experienced by members within one team in as close to

22 "real time" as possible. Video recall would seem to be a viable method to improve retrospective

23 recall validity (Bourbousson et al., 2012; Evans, Hoar, Gebotys, \& Marchesin, 2014; Gilbert, 
STRESSORS WITHIN TEAM GAMES

1 Trudel, \& Haughian, 1999). Nevertheless, a more comprehensive understanding of stressors

2 appraised as affecting both individual and team functioning is needed. Future research examining

3 interpersonal aspects of stress could also consider stressors experienced outside of games that

4 impinge on team functioning and performance during the game (e.g., organizational stressors,

5 conflict).

Furthermore, this study explored the extent to which the stressors appraised by one player

7 were also similarly appraised by teammates at the same or a different time during the game. The

8 results showed that teammates similarly reported one-third of stressors perceived as affecting a

9 player's own functioning (i.e., 34\%) and two-thirds of stressors perceived as affecting the team

10 functioning as a whole (i.e., 66\%). The most commonly shared category of stressors concerning

11 the athlete's own functioning consisted of "personal performance problems", and for team

12 functioning consisted of "teammates' performance problems". However, results for two athletes

13 did not follow this pattern. They reported one-half of the sources of stress related to their own

14 functioning (e.g., 44.5\%) and one-half related to team functioning (e.g., 55.5\%). The ratio

15 between these two categories of stressors appeared different to that of other team members. This

16 may reflect the fact that these two athletes seemed more preoccupied and perceived more sources

17 of stress related to their own functioning than other teammates did (e.g., personal performance

18 problems, mental errors, social evaluation, etc.). These players may also be viewed as a potential

19 source of stress for their teammates (e.g., "teammates' performance problems") (see Figure 1).

20 They may have influenced the emotions or behaviours of their teammates through the conscious

21 or unconscious induction of emotions (Hatfield et al., 1994; Moll, Jordet, \& Pepping, 2010).

22 Further, in the future it could be interesting to examine whether other variables may explain the

23 stress profile of these players, such as play experience, role and responsibility in the team or 
STRESSORS WITHIN TEAM GAMES

1 personality (Driskell, Goodwin, Salas, \& O'Shea, 2006). In general, future research could also

2 investigate potential variables such as team cohesion, team efficacy, coping styles, and

3 leadership, in order to provide a deeper understanding of stress experience within teams at both

4 individual- and collective-levels.

5 In addition to the individualistic or intrapersonal perspective, these results extended

6 previous studies conducted in team sports (e.g., Anshel \& Wells, 2000; Holt \& Dunn, 2004; Holt

7 \& Hogg, 2002; Madden et al., 1990; Nicholls \& Polman, 2007; Nicholls et al., 2006, 2009,

8 Noblet \& Gifford, 2002; Reeves et al., 2009) and provided information regarding the degree of

9 similarity of sources of stress appraised within a single team during a game. They showed that

10 team sport athletes seem to share and experience similar and common game-specific stressors.

11 The results provided empirical support to research calls to investigate how stressors are appraised

12 as a team and how athletes' shared appraisals may be congruent or incongruent from their

13 teammates' appraisals (Crocker, Tamminen, \& Gaudreau, 2015). To our knowledge, the present

14 study is the first to adopt an interpersonal perspective to examine the appraisal and experience of

15 stressors at collective level within a single team during a game (Tamminen \& Gaudreau, 2014).

16 Communal stressors have been defined as: "when one or more individuals perceives a stressor as

17 “our” problem (a social appraisal") vs. "my” or "your" problem (an individualistic appraisal)"

18 (Lyons et al., 1998, p. 583). The present study provides empirical support for such a statement.

19 Moreover, our results highlight how such communal stressors are arranged together within the

20 team to generate team-level configurations of stress.

21 In addition to identification of the nature and degree of similarity of the game-specific

22 stressors experienced by basketball players, it seems interesting to identify the period of time

23 during the game when teammates are affected by the same types of stressors. Based on a 
STRESSORS WITHIN TEAM GAMES

1 transactional perspective (Lazarus, 1999), stress is viewed as an ongoing dynamic process that

2 involves the individual transacting with his or her environment, appraising the situation.

3 Consequently, exploring stressors appraised by athletes during a game needs to take into account

4 temporal interplay in team members' activities. As such, the temporal view adopted in this study

5 has also allowed tracking of the way in which stressors were simultaneously experienced within

6 the team by a majority of team members during the game. The results showed different patterns

7 of synchronization within the team during the game (see Figure 2). The most frequent

8 synchronizations of team members' stressors were: (a) a player made an error and this error was

9 sufficiently serious to be simultaneously a common source of stress for him and his teammates;

10 (b) a player made an error sufficiently serious to be a common source of stress for his teammates

11 without his being concerned himself; (c) an external event was a common source of stress (e.g.,

12 referee, opposing coach); (d) several players were simultaneously concerned by personal

13 performance problems; (e) several players were simultaneously concerned by the level of team

14 performance as a source of stress; (f) several players were simultaneously concerned by the level

15 of opposing team performance as a source of stress. These findings highlighted that a stressor

16 appraised at individual level by one player may also be appraised at the same time during the

17 game by other team members (team level). These results provided additional evidence of

18 moment-to-moment stress contagion phenomena and the temporal shared appraisal and

19 experience of stressors within the team (Bourbousson et al., 2012, 2015; Hatfield et al., 1994). As

20 Vallerand and Blanchard (2000) point out, athletes' stressors may have potential consequences

21 for interpersonal appraisal and behaviours within the team. By examining the temporal interplay

22 in team members' activities, this is the first study to provide support for the synchronized

23 appraisal and experience of stressors within a team during a game. Overall, these findings invite 
STRESSORS WITHIN TEAM GAMES

1 future research to consider that phenomena of cognitive or/and emotional entrainment underlie

2 the way in which individual activities are experienced when participants are co-located members

3 of a team and share a common goal (Bourbousson et al., 2012, 2015).

4 Despite the strengths of this study, some limitations warrant mention. Firstly, the small

5 sample prevents direct generalization to other team sports, although we suspect the results

6 reported here may generalize to other similar groups and teams and present a point of departure

7 for exploring interpersonal stress and coping processes in team sports. Future research could try

8 to replicate these findings with a more comprehensive sample of basketball players at different

9 levels of expertise and/or other sport teams. Secondly, the findings should be interpreted with

10 caution because the match analysed was won (74-58 points). The results need to be supplemented

11 with other game scenarios (e.g., games that are lost or drawn) at different levels of competition to

12 gain a better understanding of the dynamics of the interpersonal processes of stress and coping.

13 Game scenarios and levels of competition are thought to place specific demands and constraints

14 on athletes and teams that could influence appraisal and coping processes at individual and team

15 levels. Future research needs to explore the characteristics of situational demands that lead to

16 communal stressors and coping strategies within teams. Finally, this study adopted a

17 conceptualization of stressors experienced within a team at two levels (individual and team), and

18 did not take into account the characteristics of the stressor, such as controllability, predictability

19 and chronicity. It would be valuable to consider the distinctive characteristics of the stressor and

20 how individual athletes vs. teams appraise and ultimately cope with stressors.

\section{5. Perspectives}

Given that team sports are played in highly competitive and demanding environments,

23 under conditions of extreme uncertainty, this study provided a unique insight into stress within 
STRESSORS WITHIN TEAM GAMES

1 the team sport setting. From both theoretical and applied perspectives, these findings highlighted

2 the importance for researchers and practitioners to improve understanding of the overall stress

3 experience of athletes within a team in order to develop action at both individual and team levels.

4 Sport psychologists may wish to prepare team sport athletes for the variety of demands that they

5 may face in the game environment. In addition, they may need to focus on teaching athletes

6 individual and communal effective coping strategies in order to avoid the risk of stress contagion

7 or choking under pressure (Gómez, Lorenzo, Jiménez, Navarro, \& Sampaio, 2015). Social skills

8 appear to be an important asset and resource to assist adaptation in the face of stress (Clarke,

9 2006). Future research needs to focus on a more holistic approach, taking into account team

10 members' sources of stress and coping responses at both individual- and collective-levels, in

11 order to improve understanding of how athletes interact within the social context of a team and to

12 develop action to improve individual and communal coping and emotional regulation (Tamminen

$13 \&$ Gaudreau, 2014). 
STRESSORS WITHIN TEAM GAMES

\section{References}

Anshel, M. H., \& Wells, B. (2000). Sources of acute stress and coping styles in competitive sport. Anxiety, Stress, \& Coping, 13, 1-26. doi: 10.1080/10615800008248331

Arnold, R., \& Fletcher, D. (2012). A research synthesis and taxonomic classification of the organizational stressors encountered by sport performers. Journal of Sport and Exercise Psychology, 34, 397-429.

Bourbousson, J., Poizat, G., Saury, J., \& Sève, C. (2011). Description of dynamic shared knowledge: An exploratory study during a competitive team sports interaction. Ergonomics, 54, 120-138. doi: 10.1080/00140139.2010.544763

Bourbousson, J., Poizat, G., Saury, J., \& Sève, C. (2012). Temporal aspects of team cognition: A case study on concerns sharing within basketball. Journal of Applied Sport Psychology, 24, 224-241. doi: 10.1080/10413200.2011.630059

Bourbousson, J., R'Kiouak, M., \& Eccles, D.W. (2015). The Dynamics of Team Coordination: A Social Network Analysis as a Window to Shared Awareness. European Journal of Work and Organizational Psychology, 24, 742-760. doi: 10.1080/1359432X.2014.1001977

Braun, V., \& Clarke, V. (2006). Using thematic analysis in psychology. Qualitative research in psychology, 3, 77-101. doi: 10.1191/1478088706qp063oa

Campo, M., Mellalieu, S., Ferrand, C., Martinent, G., \& Rosnet, E. (2012). Emotions in team contact sports: a systematic review. The Sport Psychologist, 26, 62-97.

Clarke, A. T. (2006). Coping with interpersonal stress and psychosocial health among children and adolescents: A meta-analysis. Journal of Youth and Adolescence, 35, 10-23. doi:

$10.1007 / \mathrm{s} 10964-005-9001-\mathrm{x}$ 
STRESSORS WITHIN TEAM GAMES

1 Crocker, P.R.E., Tamminen, K. A., \& Gaudreau, P. (2015). Coping in sport. In S. Hanton \& S. Mellalieu (Eds.), Contemporary advances in sport psychology: A review (pp. 28-67). New York: Routledge.

Driskell, J. E., Goodwin, G. F., Salas, E., \& O'Shea, P. G. (2006). What makes a good team player? Personality and team effectiveness. Group Dynamics: Theory, Research, and Practice, 10, 249-271. doi: 10.1037/1089-2699.10.4.249

Evans, M. B., Hoar, S. D., Gebotys, R. J., \& Marchesin, C. A. (2014). Endurance athletes' coping function use during competitive suffering episodes. European Journal of Sport Science, 14, 368-375. doi: 10.1080/17461391.2013.832803

Fletcher, D., Hanton, S., Mellalieu, S. D., \& Neil, R. (2012). A conceptual framework of organizational stressors in sport performers. Scandinavian Journal of Medicine \& Science in Sports, 22, 545-557. doi: 10.1111/j.1600-0838.2010.01242.x

Gilbert, W. D., Trudel, P., \& Haughian, L. P. (1999). Interactive decision making factors considered by coaches of youth ice hockey during games. Journal of Teaching in Physical Education, 18, 290-311.

Gómez, M. Á., Lorenzo, A., Jiménez, S., Navarro, R. M., \& Sampaio, J. (2015). Examining choking in basketball: effects of game outcome and situational variables during last 5 minutes and overtimes. Perceptual \& Motor Skills, 120, 111-124. doi: 10.2466/25.29.PMS.120v11x0

Hatfield E., Cacioppo, J., \& Rapson, R. L. (1994). Emotional contagion. New York, NY: Cambridge University Press.

Hoar, S. D., Crocker, P. R. E., Holt, N. L., \& Tamminen, K.A. (2010). Gender differences in adolescent athletes' coping with interpersonal stressors in sport: More similarities than 
STRESSORS WITHIN TEAM GAMES

differences? Journal of Applied Sport Psychology, 22, 134-149. doi:

$10.1080 / 10413201003664640$

Hoar, S. D., Kowalski, K. C., Gaudreau, P., \& Crocker, P. R. E. (2006). A review of coping in sport. In S. Hanton \& S. D. Mellalieu (Eds.), Literature Reviews in Sport Psychology (pp. 47-90). New York: Nova Science Publishers.

Holt, N. L., \& Dunn, J. G. (2004). Toward a grounded theory of the psychosocial competencies and environmental conditions associated with soccer success. Journal of Applied Sport Psychology, 16, 199-219. doi: 10.1080/10413200490437949

Holt, N. L., \& Hogg, J. M. (2002). Perceptions of stress and coping during preparations for the 1999 women's soccer World Cup finals. The Sport Psychologist, 16, 251-271.

Humphrey, S. E., \& Aime, F. (2014).Team microdynamics: towards an organizing approach to teamwork. The Academy of Management Annals, 8, 1-61. doi:10.1080/19416520.2014.904140

Lazarus, R. S. (1999). Stress and emotion: A new synthesis. London: Free Association Books.

Lazarus, R. S. (2000). How emotions influence performance in competitive sports. The Sport Psychologist, 14, 229-252.

Li, J., \& Roe, R. A. (2012). Introducing an intrateam longitudinal approach to the study of team process dynamics. European Journal of Work and Organizational Psychology, 21, 718748. doi: 10.1080/1359432X.2012.660749

Lyons, R. F., Mickelson, K. D., Sullivan, J. L. \& Coyne, J.C. (1998). Coping as communal process. Journal of Social and Personal Relationships, 15, 579-605. doi: $10.1177 / 0265407598155001$ 
STRESSORS WITHIN TEAM GAMES

1 Madden, C., Summers, J. \& Brown, D. (1990). The influence of perceived stress on coping with competitive basketball. International Journal of Sport Psychology, 21, 21-35.

3 Moll, T., Jordet, G., \& Pepping, G. J. (2010). Emotional contagion in soccer penalty shootouts:

4

5

6

7

8

9

10 celebration of individual success is associated with ultimate team success. Journal of Sports Sciences, 28, 983-992. doi: 10.1080/02640414.2010.484068

Nicholls, A. R., \& Polman, R. C. J. (2007). Stressors, coping, and coping effectiveness among international adolescent rugby union players. Journal of Sport Behavior, 30, 119-218.

Nicholls, A. R., Backhouse, S. H., Polman, R. C. J., \& McKenna, J. (2009). Stressors and affective states among professional rugby union players. Scandinavian Journal of Medicine \& Science in Sports, 19, 121-128. doi: 10.1111/j.1600-0838.2007.00757.x

Nicholls, A. R., Holt, N. L., Polman, R. C. J., \& Bloomfield, J. (2006). Stressors, coping, and coping effectiveness among professional rugby union players. The Sport Psychologist, 20, 314-329.

Nicholls, A. R., Jones, C. R., Polman, R. C. J., \& Borkoles, E. (2009). Acute sport-related stressors, coping, and emotion among professional rugby union players during training and matches. Scandinavian Journal of Medicine \& Science in Sports, 19, 113-120. doi: 10.1111/j.1600-0838.2008.00772.x

Noblet, A. J., \& Gifford, S. M. (2002). The sources of stress experienced by professional Australian footballers. Journal of Applied Sport Psychology, 14, 1-13. doi:10.1080/10413200209339007

Reeves, C. W., Nicholls, A. R., \& McKenna, J. (2009). Stressors and coping strategies among early and middle adolescent premier league academy soccer players: differences according to age. Journal of Applied Sport Psychology, 21, 31-48. doi: 10.1080/10413200802443768 
STRESSORS WITHIN TEAM GAMES

1 Scanlan, T. K., Stein, G. L., \& Ravizza, K. (1991). An in-depth study of former elite figure skaters: III. Sources of stress. Journal of Sport \& Exercise Psychology, 13, 102-120.

3 Tamminen, K. A., \& Gaudreau, P. (2014). Coping, social support, and emotion regulation in

4

5

6

7

8

9 teams. In M. R. Beauchamp \& M. A. Eys (Eds.), Group dynamics in exercise and sport psychology: Contemporary themes (2nd ed., pp. 222-239). New York: Routledge.

Theureau, J. (2003). Course-of-action analysis and course-of-action centered design. In E. Hollnagel (Ed.), Handbook of cognitive task design (pp. 55-81). Mahwah, NJ: Lawrence Erlbaum Associates. doi: 10.1201/9781410607775.ch4

Vallerand, R. J., \& Blanchard, C. M. (2000). The study of emotion in sport and exercise: historical, definitional, and conceptual perspectives. In: Hanin YL (editor). Emotions in sport (pp. 3-38). Champaign, IL: Human Kinetics. 
B

A

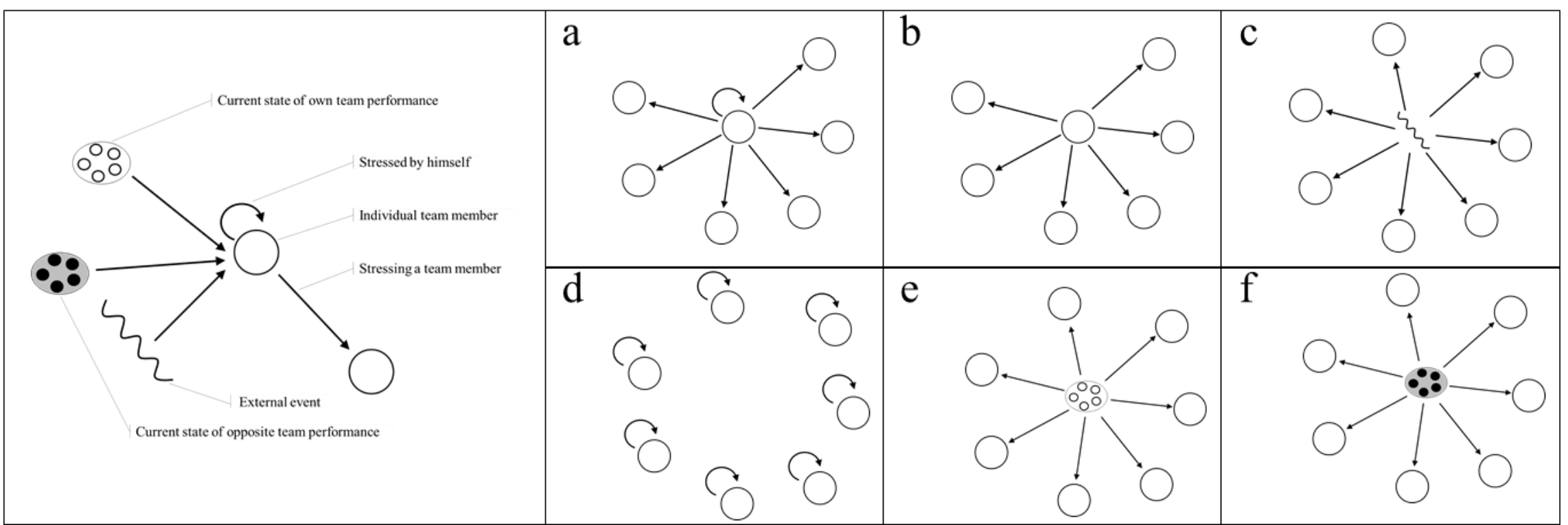

2 Figure 1. Characteristic forms of arrangement of the sources of stress within a team. A- Nomenclature of all possible types of

3 arrangements of stressors within a team. B- Characteristic forms of arrangement of stressors at a given instant within a team: (a) one

4 player makes an error and this error is important enough to be simultaneously a common source of stress for him and his teammates;

5 (b) one player makes an error important enough to be a common source of stress for his teammates without being concerned himself;

6 (c) an external event appears as a common source of stress for the team members simultaneously (e.g., referee, coach of opposite team,

7 slippery floor, etc.); (d) several players are simultaneously experiencing personal sources of stress (e.g., individual performance

8 problems); (e) several players are simultaneously experiencing the current level of team performance as a source of stress; (f) several

9 players are simultaneously experiencing the current level of opposite team performance as a source of stress. 
STRESSORS WITHIN TEAM GAMES

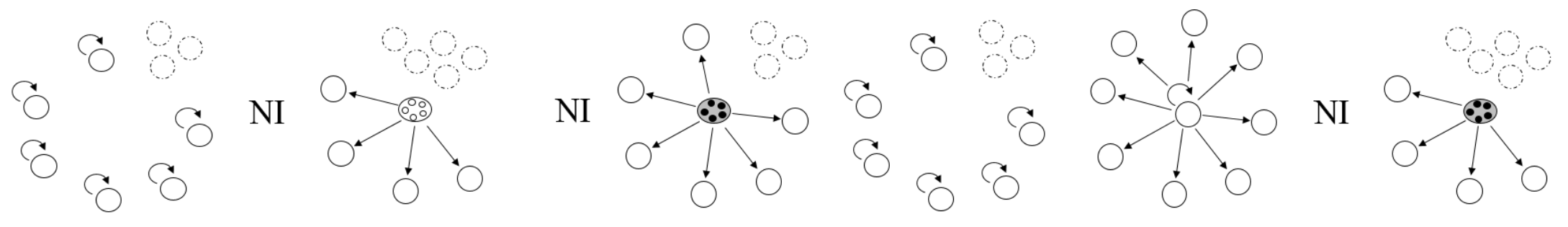

$\left[00^{\prime} 01^{\prime} 00\right]$

[00'04'00]
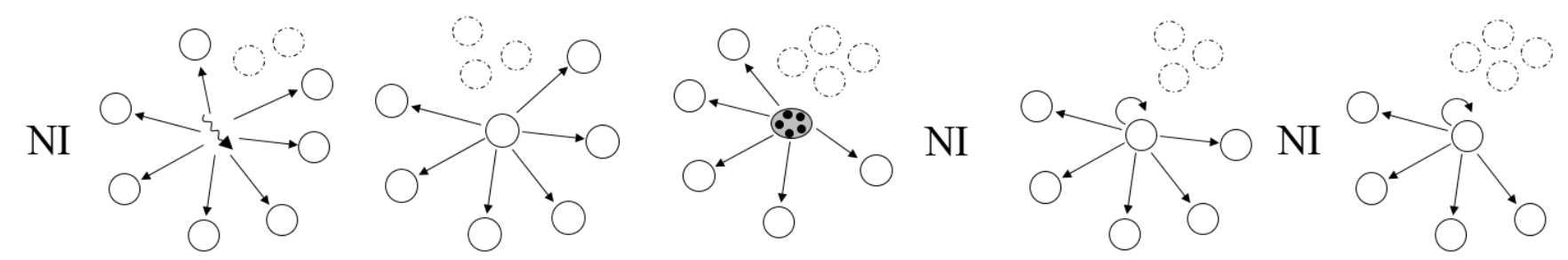

$\left[00^{\prime} 04^{\prime} 00\right]$

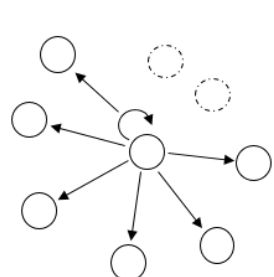

Time [h.min.s]

$\left[00^{\prime} 08^{\prime} 00\right]$

$$
\begin{aligned}
& \text { i. Team member not implied in the characteristic form of arrangement } \\
& \text { NI No characteristic form of arrangement }
\end{aligned}
$$

2 Figure 2. Changes in the forms of collective arrangements of stressors across time during a portion of the game 
STRESSORS WITHIN TEAM GAMES

$1 \quad$ Table 1

2 Illustration of the Synchronization of the Nine Players' Meaningful Units at a Given Moment of the Game

\begin{tabular}{|c|c|c|c|c|c|c|c|c|c|}
\hline $\begin{array}{l}\text { Extrinsic } \\
\text { description }\end{array}$ & $\begin{array}{l}\text { Units of activity for } \\
\text { Jules }\end{array}$ & $\begin{array}{l}\text { Units of } \\
\text { activity for } \\
\text { Chris }\end{array}$ & $\begin{array}{l}\text { Units of } \\
\text { activity for } \\
\text { Guy }\end{array}$ & $\begin{array}{l}\text { Units of } \\
\text { activity for } \\
\text { Bertrand }\end{array}$ & $\begin{array}{l}\text { Units of } \\
\text { activity for } \\
\text { Bastien }\end{array}$ & $\begin{array}{l}\text { Units of } \\
\text { activity for } \\
\text { Noé }\end{array}$ & $\begin{array}{l}\text { Units of } \\
\text { activity for } \\
\text { Niels }\end{array}$ & $\begin{array}{l}\text { Units of } \\
\text { activity for } \\
\text { Vince }\end{array}$ & $\begin{array}{l}\text { Units of } \\
\text { activity for } \\
\text { Vic }\end{array}$ \\
\hline $\begin{array}{c}\text { Noé gets } \\
\text { overwhelmed, } \\
\text { then catches up } \\
\text { with his } \\
\text { opponent and } \\
\text { blocks him }\end{array}$ & $\begin{array}{l}\text { Unit 25: defending my } \\
\text { player by keeping an } \\
\text { eye on the game } \\
\text { Here I have to be good } \\
\text { in defence... the ball has } \\
\text { been passed to the } \\
\text { opposing centre, I'm } \\
\text { monitoring my player } \\
\text { while I keep an eye on } \\
\text { the game... Noé's } \\
\text { opponent does a reverse. } \\
\text { Noé is starting to lose } \\
\text { it...but he manages to } \\
\text { come back and block the } \\
\text { shot. I tell myself that } \\
\text { Noé has done a pretty } \\
\text { good job, the opposing } \\
\text { centre handled things } \\
\text { badly, he tried to pull a } \\
\text { fake even though it } \\
\text { would have been quicker } \\
\text { to shoot, that's why Noé } \\
\text { was able to get back on } \\
\text { top of things and, right } \\
\text { when his opponent was } \\
\text { going to shoot, he was } \\
\text { able to block it. But } \\
\text { usually, here, Noé is } \\
\text { supposed to take } 2 \\
\text { points, because he fell } \\
\text { for it, and it's rare when } \\
\text { he recovers from his } \\
\text { mistakes ... }\end{array}$ & $\begin{array}{l}\text { Unit 35: } \\
\text { defending my } \\
\text { zone by } \\
\text { monitoring Noé's } \\
\text { defence } \\
\text { I'm now defending } \\
\text { the zone here...I } \\
\text { check my player } \\
\text { and the nearest } \\
\text { opponents. I say to } \\
\text { myself that we } \\
\text { might perform a } \\
\text { fast play at the next } \\
\text { attack, it would be } \\
\text { good at this stage } \\
\text { of the match. I see } \\
\text { that Noé is } \\
\text { blocking the } \\
\text { opposing centre. } \\
\text { You know, it } \\
\text { wasn't easy to do } \\
\text { this block, Noé } \\
\text { was overwhelmed. } \\
\text { I say to myself that } \\
\text { Noé's defence is } \\
\text { good today. }\end{array}$ & $\begin{array}{l}\text { Here I'm just } \\
\text { watching the } \\
\text { game, I want to } \\
\text { observe what } \\
\text { will happen. I } \\
\text { can guess that } \\
\text { the rhythm will } \\
\text { be a little slow } \\
\text { down on the } \\
\text { next attack. I } \\
\text { can see that } \\
\text { Noé has } \\
\text { guarded the } \\
\text { opposing } \\
\text { centre well and } \\
\text { that he's } \\
\text { blocked him. } \\
\text { It's well done. }\end{array}$ & $\begin{array}{l}\text { Unit 22: } \\
\text { trying to be in } \\
\text { a good } \\
\text { position for a } \\
\text { slam dunk } \\
\text { Noé gets hold } \\
\text { of the ball. I } \\
\text { see that we are } \\
\text { in a good } \\
\text { position for a } \\
\text { counter-attack, } \\
\text { and in general, } \\
\text { when you } \\
\text { suddenly get } \\
\text { hold of the } \\
\text { ball, you can } \\
\text { carry out a } \\
\text { counter-attack. } \\
\text { I say to myself } \\
\text { that if this is } \\
\text { the case, I } \\
\text { might be able } \\
\text { to perform a } \\
\text { slam dunk, } \\
\text { that's why I } \\
\text { begin to run } \\
\text { here. }\end{array}$ & $\begin{array}{l}\text { Unit 22: } \\
\text { observing } \\
\text { the qualities } \\
\text { of the game } \\
\text { While I'm on } \\
\text { the bench, } \\
\text { the } \\
\text { information } \\
\text { gathered on } \\
\text { the game and } \\
\text { opponents } \\
\text { helps me to } \\
\text { be better for } \\
\text { the next } \\
\text { match. That's } \\
\text { why I am } \\
\text { bothered } \\
\text { there by the } \\
\text { coach that's } \\
\text { in front of } \\
\text { me, I can't } \\
\text { see the game. } \\
\text { I wanted to } \\
\text { watch the } \\
\text { defence. }\end{array}$ & $\begin{array}{l}\begin{array}{l}\text { Unit 23: } \\
\text { defending } \\
\text { effectively }\end{array} \\
\text { In general, when } \\
\text { there's a real size } \\
\text { difference } \\
\text { between two } \\
\text { players, it's } \\
\text { harder for the } \\
\text { referee. That's } \\
\text { why I made a } \\
\text { small foul here } \\
\text { that wasn't } \\
\text { called. That way } \\
\text { I can guard my } \\
\text { opponent by } \\
\text { keeping close to } \\
\text { him. }\end{array}$ & $\begin{array}{l}\text { Unit 22: trying } \\
\text { to recover } \\
\text { physically } \\
\text { The unfolding } \\
\text { game now allows } \\
\text { us to make a } \\
\text { break. I try to } \\
\text { recover } \\
\text { physically. I can } \\
\text { guess that the } \\
\text { opponent won't } \\
\text { get a basket now, } \\
\text { because I can see } \\
\text { the opposing } \\
\text { centre, and he's } \\
\text { not very good } \\
\text { near the circle. } \\
\text { And Noé is } \\
\text { defending well. } \\
\text { He blocks the } \\
\text { basket. I was } \\
\text { really watching } \\
\text { the game here. }\end{array}$ & $\begin{array}{l}\text { Here, I'm } \\
\text { watching the } \\
\text { game unfold. } \\
\text { I can see the } \\
\text { tall opponent } \\
\text { who tries to } \\
\text { shoot and } \\
\text { Noé blocks } \\
\text { him. }\end{array}$ & $\begin{array}{l}\text { Unit 31: } \\
\text { defending the } \\
\text { zone } \\
\text { The coach is } \\
\text { going to remind } \\
\text { me about } \\
\text { forgetting. In the } \\
\text { defence zone, I } \\
\text { have to be in a } \\
\text { very specific } \\
\text { position and I } \\
\text { sometimes forget } \\
\text { that. Here, Noé } \\
\text { gets me to } \\
\text { reposition myself } \\
\text { on the side, and I } \\
\text { do it, of course. I } \\
\text { want to defend } \\
\text { the zone. }\end{array}$ \\
\hline
\end{tabular}




\section{STRESSORS WITHIN TEAM GAMES}

1 Table 2

2 Frequency and intraclass percentage of stressors perceived by team members during a game

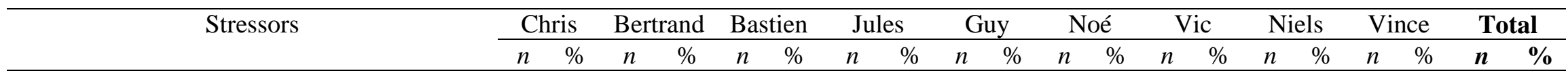

\section{A- Stressors perceived as affecting the} team functioning as whole

A-1. Level of performance of a team member

A-2. External factors perturbing team

functioning (referee, opposing coach)

A-3. Engagement and performance level of the

team (score management, collective

demotivation)

A-4. Tactical difficulty level presented by the opposition

A-5. Level of performance of opponents

(individual players, luck)

A-6. Ratio of power

\section{B- Stressors perceived as affecting a player's own functioning}

\section{B-1. Personal performance problems}

$B$-2. Mental errors (concentration, negative emotions)

B-3. Social demands (from teammates, perception of coach's satisfaction, proving your worth)

B-4. Personal unfavourable game events

(opposition, collective organization, score,

slippery floor)

B-5. Physical demands (pain, fatigue)

B-6. Coach criticism

\begin{tabular}{lllllllllllllllllllllllll}
$\mathbf{4 5}$ & $\mathbf{6 9}$ & $\mathbf{5 2}$ & $\mathbf{6 2}$ & $\mathbf{4 7}$ & $\mathbf{7 0}$ & $\mathbf{1 0 9}$ & $\mathbf{7 6}$ & $\mathbf{4 2}$ & $\mathbf{6 6}$ & $\mathbf{7 4}$ & $\mathbf{6 7}$ & $\mathbf{3 0}$ & $\mathbf{5 4}$ & $\mathbf{7 6}$ & $\mathbf{6 5}$ & $\mathbf{5 0}$ & $\mathbf{5 7}$ & $\mathbf{5 2 2}$ & $\mathbf{6 6}$ \\
& & & & & & & & & & & & & & & & & & \\
17 & 38 & 26 & 50 & 28 & 60 & 68 & 62 & 23 & 55 & 39 & 53 & 12 & 40 & 28 & 38 & 24 & 48 & 265 & 51 \\
7 & 16 & 5 & 10 & 1 & 2 & 14 & 13 & 1 & 2 & 13 & 18 & 6 & 20 & 12 & 16 & 8 & 16 & 67 & 13 \\
6 & 13 & 11 & 21 & 2 & 4 & 10 & 9 & 3 & 7 & 9 & 12 & 4 & 13 & 7 & 10 & 5 & 10 & 57 & 11 \\
& & & & & & & & & & & & & & & & & & & \\
8 & 18 & 4 & 8 & 5 & 11 & 8 & 7 & 5 & 12 & 4 & 5 & 1 & 3 & 6 & 8 & 5 & 10 & 46 & 9 \\
6 & 13 & 5 & 10 & 9 & 19 & 4 & 4 & 7 & 17 & 3 & 4 & 2 & 7 & 6 & 8 & 3 & 6 & 45 & 9 \\
1 & 2 & 1 & 2 & 2 & 4 & 5 & 5 & 3 & 7 & 6 & 8 & 5 & 17 & 14 & 19 & 5 & 10 & 42 & 8 \\
\hline
\end{tabular}

$\begin{array}{llllllllllllllllllll}20 & 31 & 32 & 38 & 20 & 30 & 35 & 24 & 22 & 34 & 37 & 33 & 26 & 46 & 39 & 35 & 37 & 43 & 268 & 34\end{array}$

$\begin{array}{llllllllllllllllllll}6 & 30 & 15 & 47 & 8 & 40 & 10 & 29 & 7 & 32 & 15 & 41 & 17 & 65 & 21 & 54 & 14 & 38 & 113 & 42\end{array}$

$\begin{array}{llllllllllllllllllll}4 & 20 & 3 & 9 & 4 & 20 & 9 & 26 & 4 & 18 & 5 & 14 & 3 & 12 & 5 & 13 & 9 & 24 & 46 & 17\end{array}$

$\begin{array}{llllllllllllllllllll}1 & 5 & 8 & 25 & 1 & 5 & 4 & 11 & 4 & 18 & 8 & 22 & 2 & 8 & 6 & 15 & 8 & 22 & 42 & 16\end{array}$

$\begin{array}{llllllllllllllllllll}4 & 20 & 4 & 13 & 6 & 30 & 4 & 11 & 4 & 18 & 5 & 14 & 1 & 4 & 2 & 5 & 3 & 8 & 33 & 12\end{array}$

$\begin{array}{llllllllllllllllllll}5 & 25 & 2 & 6 & 1 & 5 & 8 & 23 & 3 & 14 & 2 & 5 & 2 & 8 & 2 & 5 & 1 & 3 & 26 & 10\end{array}$

$\begin{array}{llllllllllllllllllll}0 & 0 & 0 & 0 & 0 & 0 & 0 & 0 & 0 & 0 & 2 & 5 & 1 & 4 & 3 & 8 & 2 & 5 & 8 & 3\end{array}$ 